\title{
PERANCANGAN SISTEM INFORMASI KEUANGAN PADA TOKO KUE IBU DANIS BERBASIS JAVA
}

\author{
Natanael $^{1}$, Reko Syarief Hidayatullah ${ }^{2}$, Nurullaeli ${ }^{3}$ \\ Program Studi Teknik Informatika, Fakultas Teknik dan Ilmu Komputer, \\ Universitas Indraprasta PGRI \\ Jalan Raya Tengah No. 80, Kelurahan Gedong, Pasar Rebo, Jakarta Timur \\ natanael.manurung96@gmail.com ${ }^{1}$, erlanalviano@gmail.com ${ }^{2}$, leli.biofisika@gmail.com³
}

\begin{abstract}
Abstrak
Tujuan penelitian adalah untuk mempermudah dalam pengelolaan data keuangan yang terdapat pada Toko Kue Ibu Danis agar pekerjaan menjadi lebih efektif dan efisien, selain itu perancangan ini dapat membantu menyelesaikan permasalahan pekerjaan yang berkenaan dengan pembuatan laporan bulanan sehingga dapat terselesaikan dengan cepat, tepat, akurat guna mengefisienkan waktu pekerjaan. Metode penelitian yang digunakan dalam sistem keuangan ini adalah metode Research and Development $(\mathrm{RnD})$ yang dapat tumbuh dari adanya potensi dan masalah dengan melakukan penelitian dan pengembangan melalui berbagai media yang memuat informasi yang dibutuhkan, menganalisa kebutuhan, perancangan, implementasi, pengkodean, dan pengujian. Setelah melakukan penelitian, peneliti menarik kesimpulan bahwa dibutuhkan suatu sistem yang relevan untuk sistem keuangan di Toko Kue Ibu Danis. Aplikasi keuangan ini tercipta dengan dukungan pemrograman Java serta database MySQL.
\end{abstract}

Kata Kunci: Sistem Informasi, Keuangan, Java, MySQL.

\begin{abstract}
The purpose of the study is to facilitate the management of financial data contained in the Ibu Danis Pastry Shop so that the work becomes more effective and efficient, besides this design can help solve work problems relating to making monthly reports so that it can be resolved quickly, precisely, accurately in order to make it efficient work time. The research method used in this financial system is the Research and Development $(R n D)$ method that can grow from the potential and problems by conducting research and development through various media that contain the information needed, analyze needs, design, implementation, coding, and testing. After conducting research, the researcher draw the conclusion that a system that is relevant to the financial system in the Danis Pastry Shop is needed. This financial application was created with the support of Java programming and MySQL databases.
\end{abstract}

Keywords: Information Systems, Finance, Java, MySQL.

\section{PENDAHULUAN}

Perkembangan teknologi dirasakan semakin maju dengan pesat, terutama dalam bidang komputer. Komputer saat ini bukan hanya menjadi media pengajaran, usaha, informasi, dan hiburan yang baru tetapi juga mampu menjadi suatu ilmu baru yang berguna bagi perkembangan komputer itu sendiri dan manusia. Di dalam dunia usaha, penggunaan komputer bukanlah merupakan hal yang baru karena komputer dapat dijadikan sebagai alat bantu untuk melakukan aktivitas misalnya dalam pengolahan data, pembuatan laporan, dan penyimpanan data dimana hal itu dapat menghasilkan suatu informasi yang cepat, tepat, dan akurat. Perancangan adalah proses pengembangan spesifikasi baru berdasarkan rekomendasi hasil analisis sistem (Muhammad, 2012). Sistem adalah suatu jaringan kerja dari prosedur-prosedur yang saling berhubungan, terkumpul bersama-sama untuk melakukan suatu kegiatan atau untuk tujuan tertentu (Yakub, 2012). Maka dari itu, perancangan sistem adalah spesifikasi umum dan terinci dari pemecahan masalah berbasis komputer yang telah dipilih selama tahap analisis (Susanto, 2017). Selain itu, informasi merupakan sekumpulan fakta (data) yang diorganisasikan dengan cara tertentu sehingga mereka mempunyai arti bagi penerima (Sutarman, 2014). Sehingga, sistem informasi adalah sebuah rangkaian prosedur formal dimana data dikelompokkan, diproses menjadi informasi, dan didistribusikan kepada pemakai (Abdul, 2014). Hal ini dapat menjadi penggerak bagi penggunaan informasi, ketika fungsi informasi adalah utamanya menambah pengetahuan atau mengurangi ketidakpastian pemakai informasi (Hutahaean, 2015). Toko Kue Ibu Danis merupakan usaha dagang yang bergerak di bidang makanan. Proses sistem informasi keuangan Toko Kue Ibu Danis masih menerapkan sistem 
basis data manual yang proses keuangannya ditulis pada kertas. Sistem keuangan yang digunakan tersebut masih dirasa kurang efektif dan efisien karena membutuhkan waktu yang cukup lama dalam proses penyimpanan data transaksi keuangan yang ada pada toko tersebut. Penggunanan sistem berbasis komputer yang lebih baik sangat diperlukan dan diharapkan dapat membantu dalam proses pengolahan data transaksi keuangan berupa pemasukan, pembelian maupun pengeluaran pada Toko Kue Ibu Danis sehingga dapat menyajikan kebutuhan informasi keuangan yang tepat dan akurat. Berdasarkan uraian permasalahan di atas, maka diperlukan program aplikasi keuangan untuk mempermudah proses pengolahan data keuangan di Toko Kue Ibu Danis, sehingga peneliti mencoba memilih judul "Perancangan Sistem Informasi Keuangan Pada Toko Kue Ibu Danis Berbasis Java".

\section{PENELITIAN YANG RELEVAN}

Penelitian oleh Heribertus Yulianton, Felix Andreas Sutanto, dan Sri Mulyani (2014) dengan judul Rancang Bangun Sistem Informasi Keuangan Berbasis Area untuk Pengusaha Kecil (Studi Kasus Batik Wijayanti Semarang), adapun tujuan dari peneltiian tersebut adalah pencatatan transaksi keuangan yang cermat dan tepat sesuai penggunannya akan menghasilkan informasi yang akurat dan up to date bagi setiap pemakai dan yang membutuhkan. Tak terkecuali perusahaan kecil dengan volume transaksi yang tidak sedikit di bagian pusat dan cabang juga membutuhkan pembukuan transaksi keuangan yang dimilikinya (Yulianton et al., 2014).

Penelitian oleh Sri Rahayu dan Putri Arianti Rahayu (2015) dengan judul Perancangan Sistem Informasi Pengelolaan Keuangan Berbasis Web Di Sekolah Menengah Kejuruan Islam Atturmudziyyah Garut. Tujuan dari penelitian ini adalah membuat sebuah sistem informasi pengelolaan keuangan berbasis web untuk SMK Islam Atturmudziyyah Garut yang dapat diakses kapan saja serta adanya fasilitas untuk siswa agar bisa mengecek data keuangan masing-masing dengan mudah (Rahayu \& Rahayu, 2015).

\section{METODE PENELITIAN \\ Teknik Pengumpulan Data}

Dalam penelitian ini peneliti menggunakan metode penelitian dan pengembangan atau lebih dikenal dengan Research and Development $(\mathrm{RnD})$. Metode penelitian dan pengembangan adalah metode penelitian yang digunakan untuk menghasilkan produk tertentu, dan menguji keefektifan produk tersebut (Sugiyono, 2013). Metode pengumpulan data yang dilakukan oleh peneliti dalam mengumpulkan data-data serta informasi menggunakan beberapa teknik, antara lain:

\section{a. Studi Pustaka}

Pengumpulan data dan informasi dari kutipan buku-buku, artikel-artikel yang berguna untuk memperlengkap data, serta catatan sebagai referensi dan dasar pemikiran yang sekiranya mempunyai hubungan terkait dengan permasalahan pengolahan data keuangan.

\section{b. Observasi}

Pengumpulan data dengan melakukan peninjauan secara langsung ke tempat penelitian dengan mengamati pelaksanaan sistem yang sedang beroperasi dan mengamati jalannya informasi yang ditinjau dari segi yang dianggap penting.

\section{c. Wawancara}

Pengumpulan data dengan cara mengajukan beberapa pertanyaan secara langsung kepada pemilik toko kue guna mendapatkan penjelasan dari masalah-masalah yang kurang jelas.

\section{HASIL DAN PEMBAHASAN}

Proses sistem keuangan yang diusulkan pada Toko Kue Ibu Danis dapat dideskripsikan sebagai berikut, yaitu:

a. Pendataan Supplier

Proses pendataan supplier ini dilakukan oleh bagian kasir, selanjutnya data tersebut berfungsi untuk menyimpan data supplier dalam melakukan transaksi pembelian kue nantinya.

b. Pendataan Kue

Proses pendataan kue ini digunakan untuk menyimpan informasi data stok kue dalam melakukan transaksi pembelian dari supplier dan transaksi pemasukan dari salinan struk penjualan. 
c. Pendataan Kebutuhan

Proses pendataan kebutuhan ini digunakan untuk menyimpan data daftar kebutuhan dalam melakukan transaksi pengeluaran nantinya.

d. Pembelian

Proses transaksi pembelian ini dimulai dari kasir yang mengecek apakah produk masih tersedia atau tidak, jika produk tidak tersedia maka kasir akan membuat bukti pembelian sebagai data stok habis yang akan diberikan kepada supplier.

e. Pemasukan

Proses transaksi pemasukan ini dilakukan setelah melakukan proses transaksi pembelian, yang secara otomatis akan menambahkan data stok kue dalam proses pendataan kue, sehingga kasir dapat meng-input data pemasukan.

f. Pengeluaran

Proses transaksi pengeluaran ini dilakukan dengan memanggil file data kebutuhan dan data kue yang tersimpan untuk menghitung total pengeluaran dari masing-masing kebutuhan dalam membuat sebuah kue.

g. Laporan

Proses laporan dilakukan dengan sistem terkomputerisasi, dalam bentuk cetakan dokumen.

\section{Diagram Konteks Sistem yang Diusulkan}

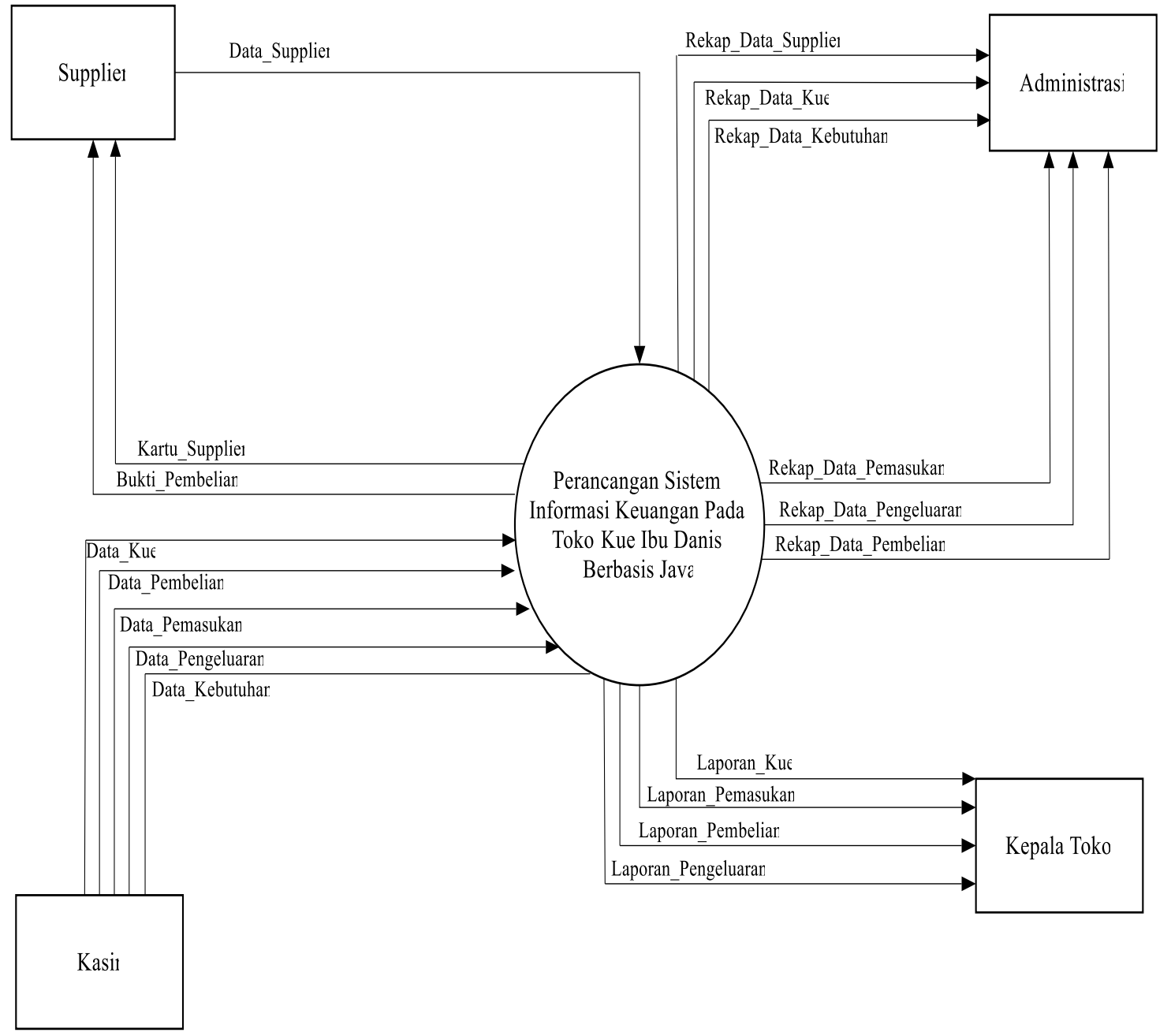

Gambar 1. Diagram Konteks 


\section{Diagram Nol Sistem yang Diusulkan}

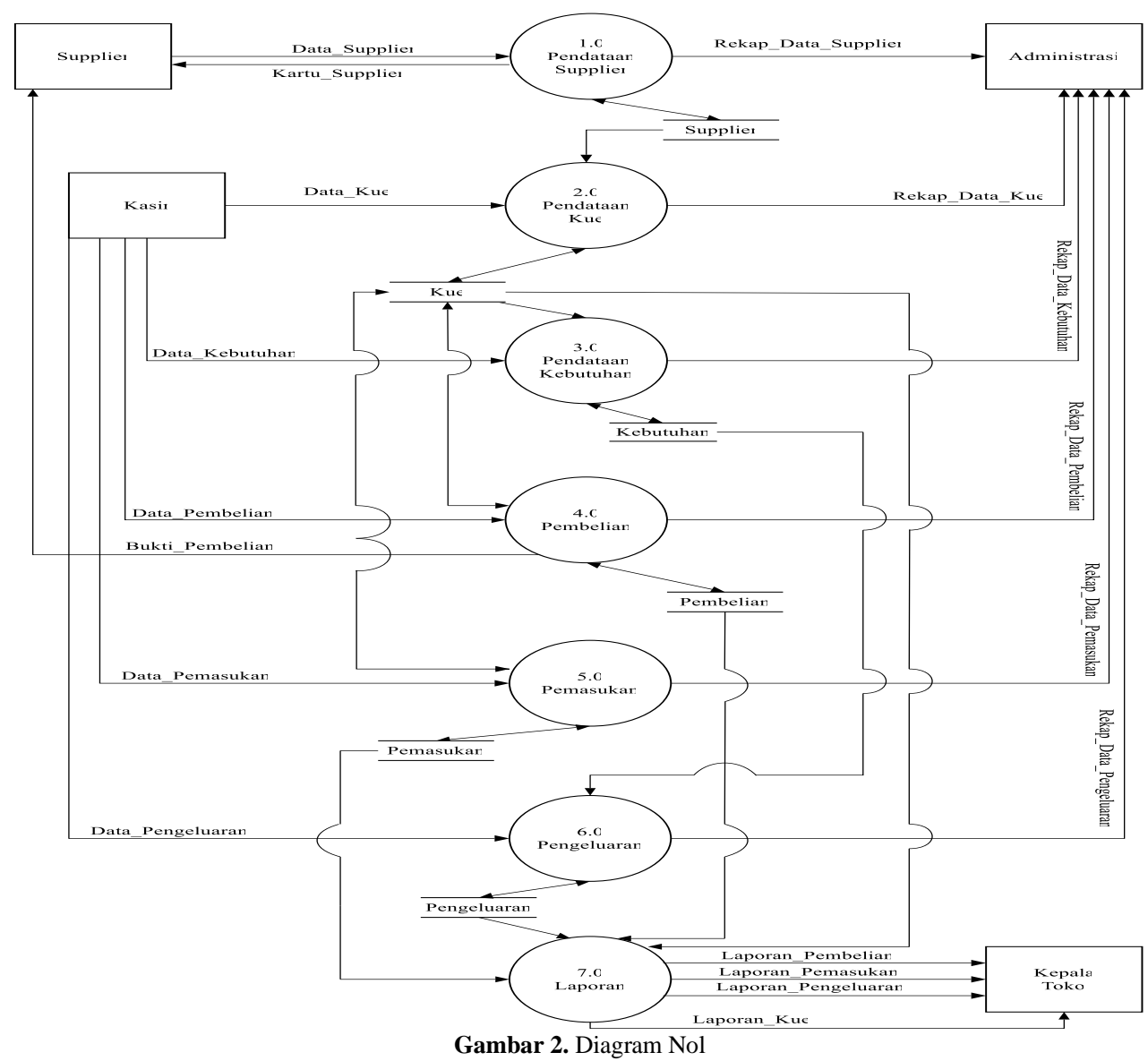

\section{Entity Relationship Diagram (ERD)}

Entitiy Realtionship Diagram (ERD) adalah diagram yang menggambarkan keterkaitan antara tabel beserta dengan field-field di dalamnya pada suatu database sistem (Pratama \& Pratama, 2014).

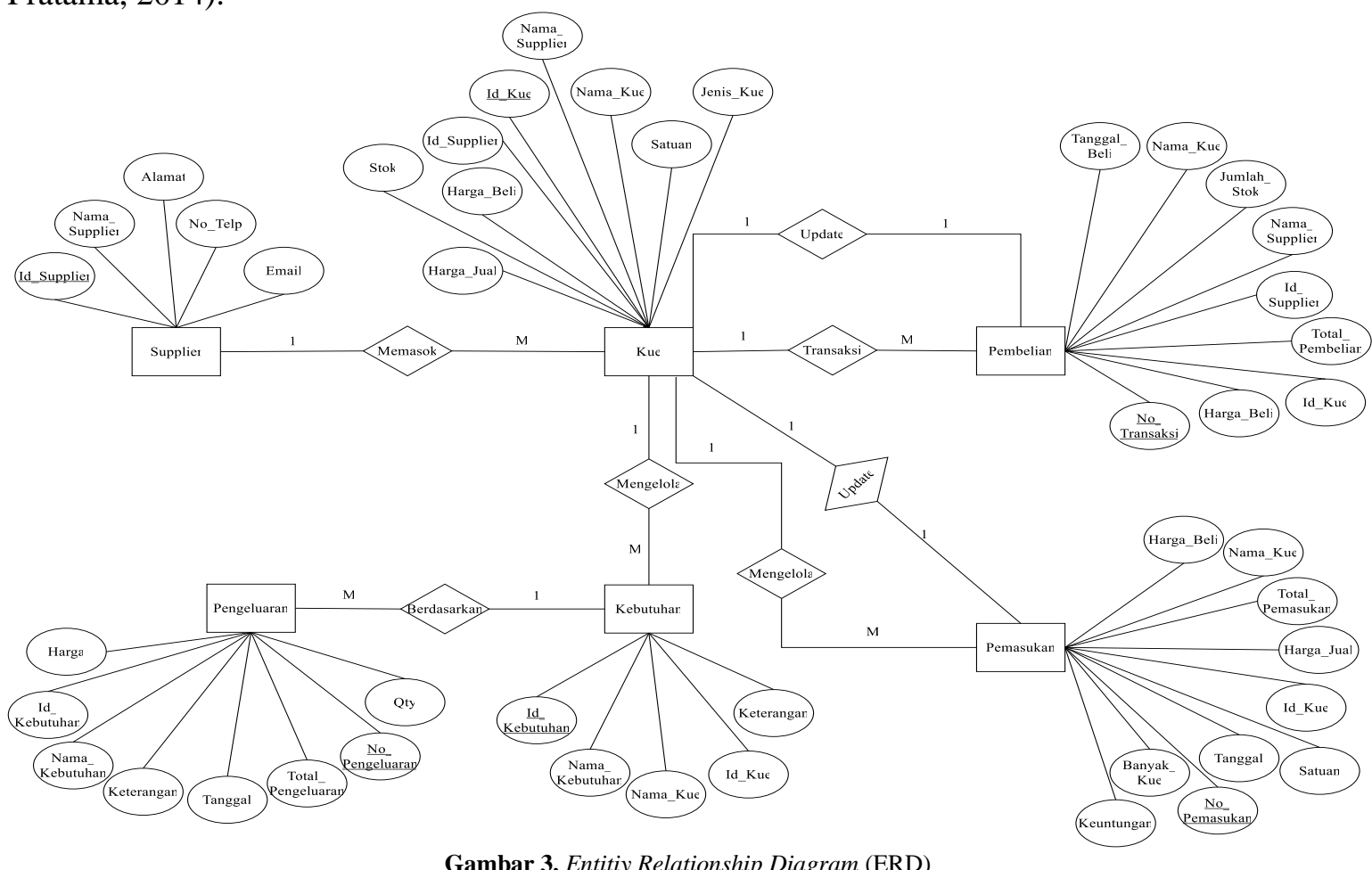

Gambar 3. Entitiy Relationship Diagram (ERD) 


\section{Tampilan Layar, Tampilan Format Masukan, dan Tampilan Keluaran}

Berikut ini tahap implementasi dan pengujian pada software program yang telah dibuat oleh dengan bahasa pemrograman Java serta database MySQL.

\section{Tampilan Login}

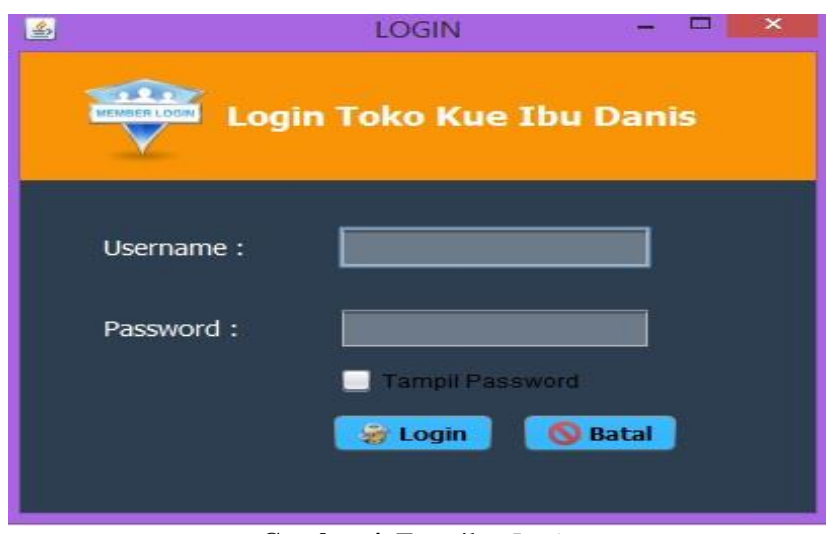

Gambar 4. Tampilan Login

Tampilan login ini sebagai kunci sebelum kita memasuki program utama agar tidak sembarangan orang yang dapat mengakses program ini.

\section{Tampilan Menu Utama}

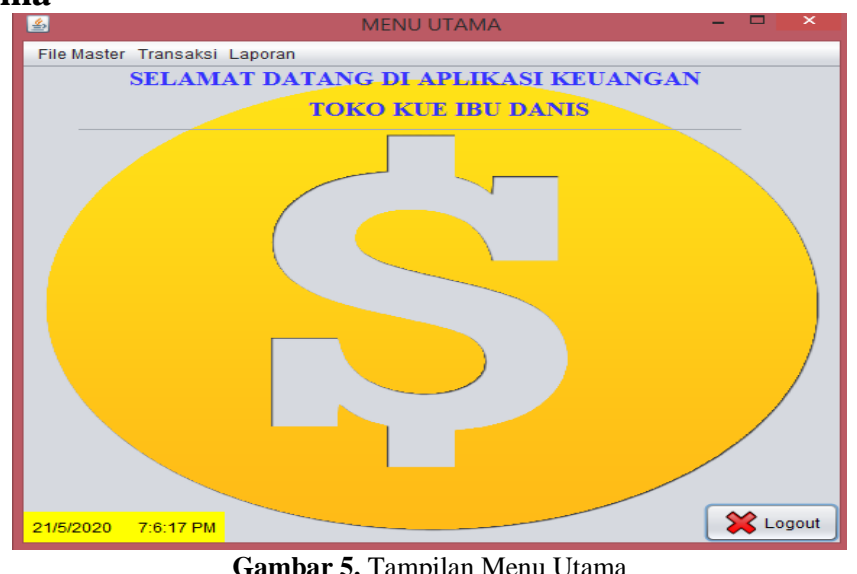

Gambar 5. Tampilan Menu Utama

Tampilan menu utama di atas, berfungsi untuk memilih submenu yang sesuai dengan kegiatan yang dibutuhkan.

\section{Tampilan Pemasukan}

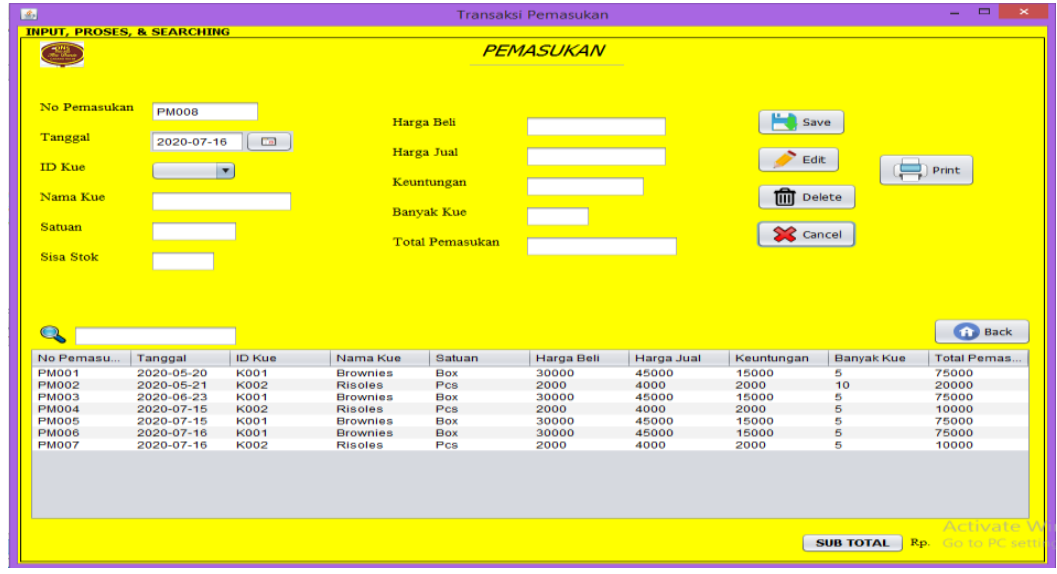

Gambar 6. Tampilan Pemasukan

Tampilan pemasukan di atas, berfungsi untuk meng-input data pemasukan dari hasil penjualan. 


\section{Tampilan Pembelian}

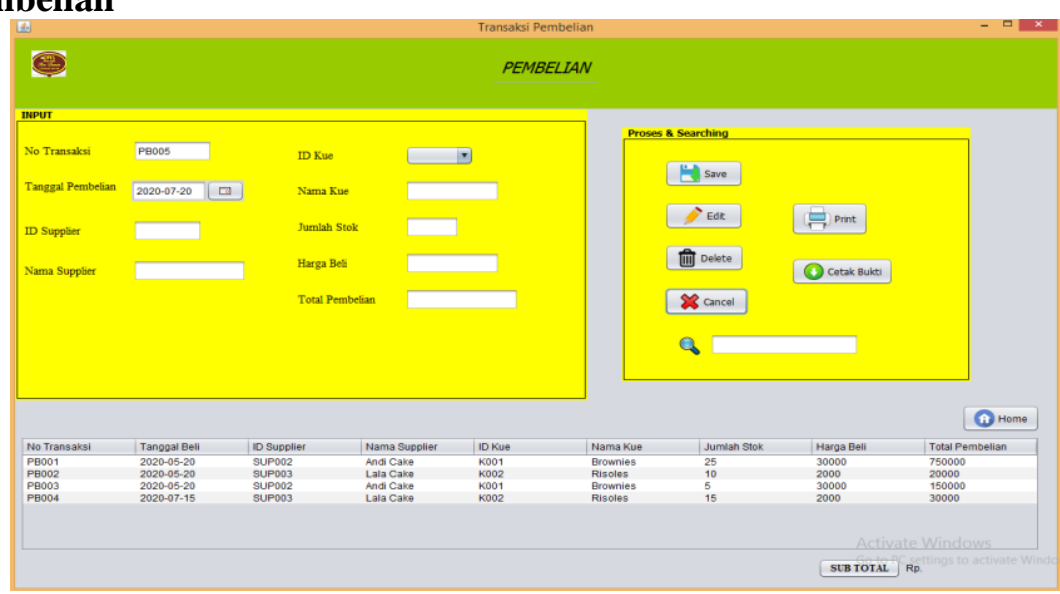

Gambar 7. Tampilan Pembelian

Tampilan pembelian di atas, berfungsi untuk meng-input data pembelian stok kue jika sedang tidak tersedia.

\section{Tampilan Pengeluaran}

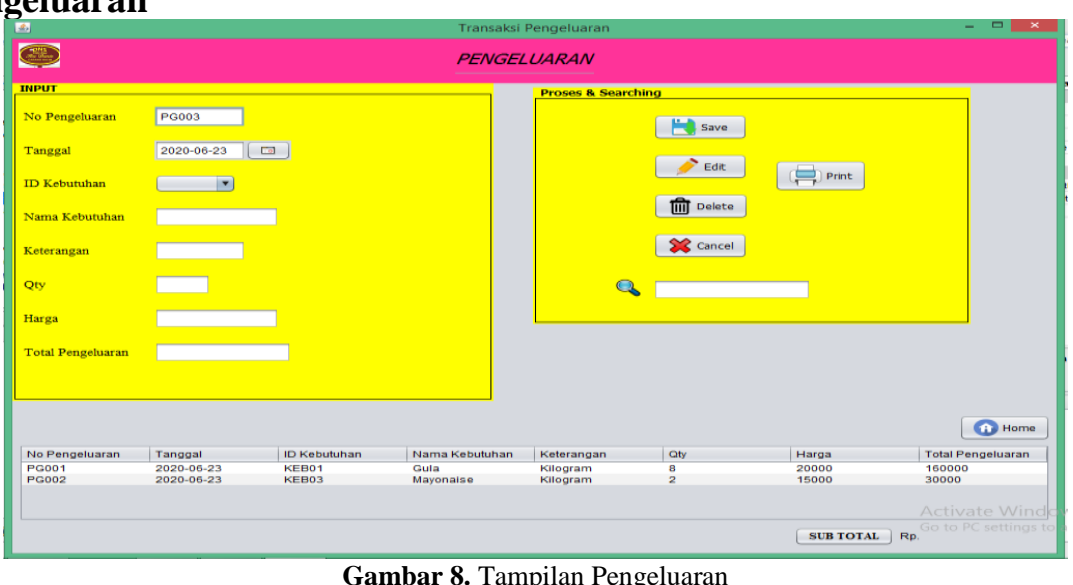

Tampilan pengeluaran di atas, berfungsi untuk meng-input data pengeluaran terhadap kebutuhan kue.

\section{Tampilan Laporan Pemasukan}

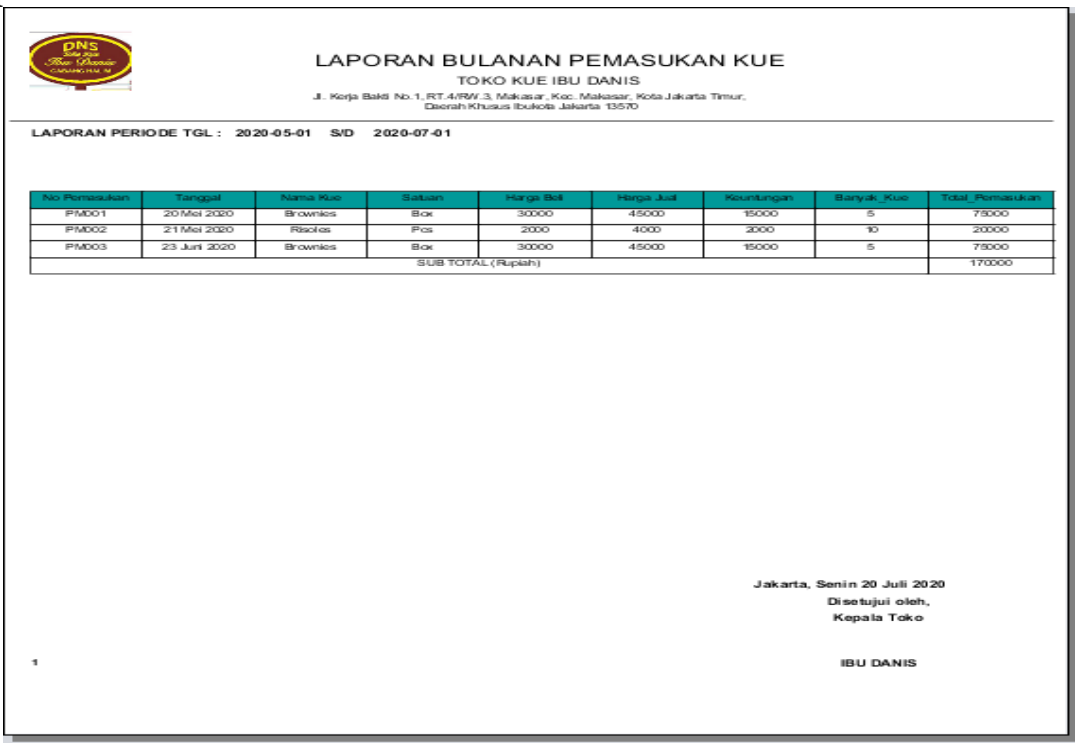

Gambar 9. Tampilan Laporan Pemasukan 
Tampilan di atas, berisi laporan pemasukan dari hasil penjualan yang ada di Toko Kue Ibu Danis.

\section{Tampilan Laporan Pembelian}

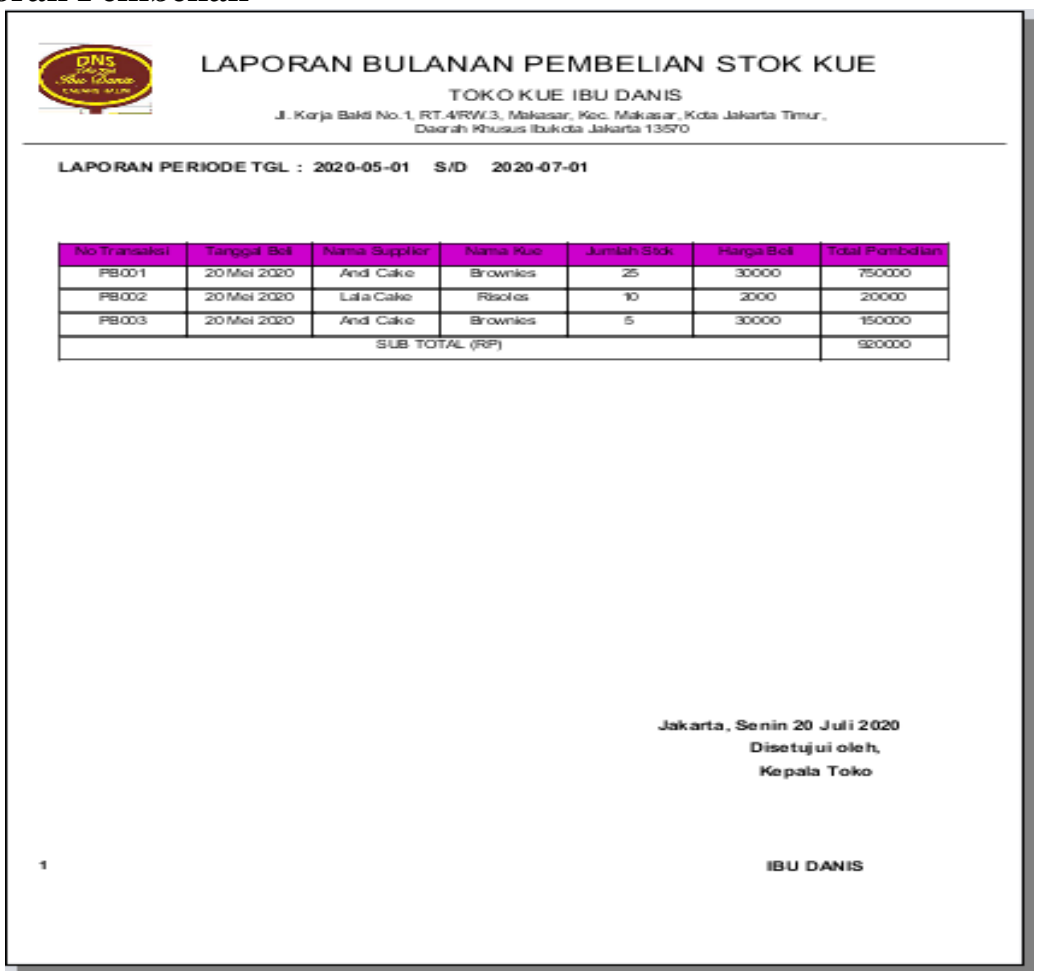

Gambar 10. Tampilan Laporan Pembelian

Tampilan di atas, merupakan laporan pembelian stok kue yang dilakukan oleh Toko Kue Ibu Danis.

\section{Tampilan Laporan Pengeluaran}

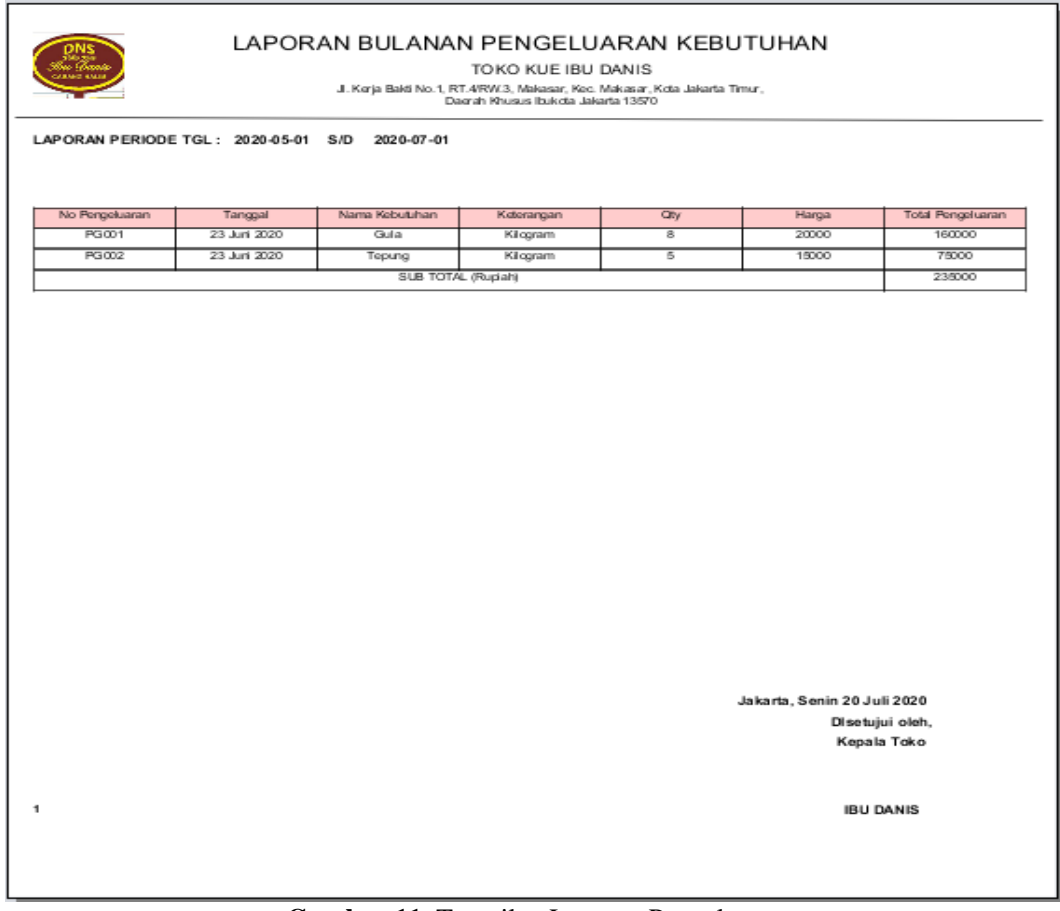

Gambar 11. Tampilan Laporan Pengeluaran

Tampilan di atas, merupakan laporan pengeluaran akan kebutuhan pengolahan kue. 


\section{SIMPULAN}

Dengan dibuatnya sistem informasi keuangan, semua kegiatan yang berhubungan dengan pengolahan data keuangan menjadi lebih akurat dan cepat. Kecepatan dan keakuratan dari hasil perancangan sistem ini juga membutuhkan partisipasi aktif dari pemakai sistem, terutama sisi ketelitian para pengguna yang menangani secara langsung manfaat yang ada pada sistem ini, dimana sistem informasi keuangan yang telah terkomputerisasi ini dapat mempermudah pihak toko kue dalam menganalisa data keuangan secara lebih terkonsep, efektif, dan up to date dalam pemeliharan datanya. Selanjutnya, dengan adanya penyimpanan data dalam bentuk database membuat aktivitas karyawan Toko Kue Ibu Danis menjadi lebih mudah dalam pengolahan perhitungan data transaksi, sehingga menghasilkan laporan bulanan transaksi keuangan yang akurat dan penyimpanan arsip data yang lebih aman.

\section{DAFTAR PUSTAKA}

Abdul, K. (2014). Pengenalan Sistem Informasi Edisi Revisi. Andi Offest, Yogyakarta.

Hutahaean, J. (2015). Konsep sistem informasi. Deepublish.

Muhammad, S. (2012). Analisa dan Perancangan Sistem. Jakarta: Lentera Ilmu Cendekia.

Pratama, I. P. A. E., \& Pratama, I. P. A. E. (2014). Sistem informasi dan implementasinya. Informatika.

Rahayu, S., \& Rahayu, P. A. (2015). Perancangan Sistem Informasi Pengelolaan Keuangan Berbasis Web di Sekolah Menengah Kejuruan Islam Atturmudziyyah Garut. Jurnal Algoritma, 14(2), 538-545. https://doi.org/10.33364/algoritma/v.14-2.538

Sugiyono, P. D. (2013). Metode penelitian kuantitatif dan kualitatif dan R\&D [Quantitative and qualitative and R \& D research methods]. Bandung, Indonesia: Alfabeta.

Susanto, A. (2017). Sistem Informasi Manajemen: Konsep dan Pengembangan Secara Terpadu. Bandung: Lingga Jaya.

Sutarman. (2014). Konsep Sistem Informasi. Andi Offset.

Yakub, J. B. (2012). Pengantar Sistem Informasi. Graha Ilmu.

Yulianton, H., Sutanto, F. A., \& Mulyani, S. (2014). Rancang Bangun Sistem Informasi Keuangan Berbasis Area untuk Pengusaha Kecil ( Studi Kasus Batik Wijayanti Semarang ). Jurnal Teknologi Informasi DINAMIK, 19(2), 137143. 